\title{
Clinical Sub-Groups of Multiple Sclerosis in Relation to HLA: DR Alleles as Possible Markers of Disease Progression
}

\author{
Pierre Duquette, Francine Décary, Juliana Pleines, Denise Boivin, \\ Gilles Lamoureux, James B.R. Cosgrove $\dagger$, Yves Lapierre
}

\begin{abstract}
We have examined the distribution of HLA antigens in 70 multiple sclerosis (MS) patients divided in three groups defined according to clinical criteria: benign MS, severe MS, cerebellar MS. We have found a significant association between severe MS and HLA-DR2, and between benign MS of more than 15 years of evolution and HLA-DR3. We review previous work along the same line and conclude that the association of HLA antigens with "clinical subgroups of MS" could indicate a genetically based heterogeneity of the disease and offer help in establishing a prognosis.
\end{abstract}

RÉSUMÉ: Les sous-groupes cliniques de sclérose en plaques en relation avec l'HLA: allèles DR comme vraisemblables marqueurs de la progression de maladie Nous avons étudié la distribution des antigènes HLA chez 70 patients atteints de sclérose en plaques (SEP) regroupés, selon des critères d'évolution clinique, en SEP bénigne, SEP sévère et SEP cérébelleuse. Nous avons retrouvé une association significative entre la SEP sévère et le HLA-DR2 d'une part, et entre la SEP bénigne de plus de 15 ans d'évolution et le HLA-DR3 d'autre part. Nous résumons les publications antérieures du même ordre et concluons que l'association entre des antigènes HLA et des sous-groupes cliniques de la SEP peuvent indiquer une hétérogénéité de la maladie fondée génétiquement et contribuer à la formulation du pronostic évolutif.

Can. J. Neurol. Sci. 1985: 12:106-110

Multiple sclerosis (MS) is known to be associated with certain HLA alleles in some populations, mostly of Caucasian extraction. The most constant association is with DR2 (Ebers, 1983). The significance of this association is not clear and the study of MS multiplex families has further obscured the issue (Ebers and Paty, 1982 \& 1983).

It has now been shown that, for example, in diabetes, myasthenia gravis and systemic lupus erythematosus different clinical sub-groups of these diseases are associated with different HLA alleles (Cudworth, 1978; Engel, 1979; Bell and Rigby, 1984). Having examined a large number of MS patients over the years, we have been impressed, despite the protean character of the disease, with the similarity of its course in some categories of patients. Clinical patterns of evolution would be reproduced from one patient to another. Patients with benign MS usually have an early onset, their bouts imply lesions of afferent structures, are short-lasted, and they recover totally, or almost so. Patients with severe MS tend to have critical lesions at onset, or a short time thereafter; impairment is diffuse. What we call cerebellar MS appeared to us as particularly characteristic, almost to the point of considering it as a distinct clinical entity: onset is usually in the early twenties, evolution is progressive, sex distribution is equal, cerebellar signs are diffuse and prominent. We do not know if this variability of expression of the disease is attributable to factors related to the disease agents, or to hostrelated factors, or to an interaction between the two. In order to study host-related factors, we have examined the HLA antigen distribution in what we consider to be well-characterized clinical sub-groups of MS: the benign form, the severe form and the cerebellar form. It is recognized that these sub-groups do not encompass the total range of clinical expression of MS. They were selected partially because of availability of patients and also because they allowed for strict criteria of definition.

From Hôpital Notre-Dame (Drs. Duquette and Pleines). Canadian Red Cross (Drs. Décary and Boivin) Institut Armand Frappier (Dr. Lamoureux) and Neurological Institute (Drs. Cosgrove and Lapierre) in Montréal. +Dr Cosgrove - deceased May 11, 1984.

Received August 28, 1984. Accepted in revised form February 22, 1985.

Reprint requests to: Dr. Pierre Duquette, Hôpital Notre Dame, 1560 Est Rue Sherbrooke, Montreal, Quebec. Canada H2L 4N1 


\section{METHODS}

\section{Clinical definitions}

The benign form of MS was defined as that allowing an evolution of 10 years or more from onset of symptoms, without ever reaching a level of 3 on the Kurtzke functional score. Because some patients have been known to change from a benign to a severe course between 10 and 15 years, and because this reversal is very rare after 15 years of evolution, this group was divided in 2 sub-groups, one of 10 to 14 years, the other of 15 years and more of evolution. The severe group included patients who reached a permanent score of 7.5 (or more) within 5 years of evolution. The cerebellar form of MS was defined as the development of severe and diffuse cerebellar impairment (including a posture or action tremor of the arms) combined with bilateral internuclear ophthalmoplegia, within 5 years of evolution.

\section{Clinical material}

This study was done retrospectively. Once clinical sub-groups were defined, charts were reviewed and suitable candidates were identified. Patients who were willing to collaborate were included in the study without further selection. The investigators who performed the HLA typings were unaware of the group to which the patient had been allocated, and the assignment of patients to clinical sub-groups was done before HLA results were available.

Table I shows the clinical characteristics of the patients studied. A total of 70 patients were included. All were regularly attending the MS clinic, either at Notre-Dame Hospital (60 patients) or at the Montreal Neurological Institute ( 10 patients). All had definite MS according to Rose et al. criteria (Rose and Ellison, 1976). Thirty-seven had had lumbar punctures, 23 of which showed oligoclonal bands and 26 elevated $\operatorname{lgG}$ levels. The duration of the illness averaged 13.1 years for the whole group. Age of onset ranged from 13 to 45 years, with an average of 24.5 years. All patients, as well as controls, were of Caucasian extraction; none were interrelated. The control population consisted of 125 unselected healthy subjects who had been typed for their HLA-A and B antigens in the course of a population genetics study. Sixty of them had been typed for HLA-DR antigens. This control population was typed in one laboratory (F.D.).

Table 1: Clinical Characteristics of the Population Studied

\begin{tabular}{|c|c|c|c|c|c|c|c|c|c|}
\hline & \multicolumn{3}{|c|}{ NUMBER OF PATIENTS } & \multicolumn{3}{|c|}{ DURATION OF DISEASE (YEARS) } & \multicolumn{3}{|c|}{ AGE OF ONSET (YEARS) } \\
\hline & Total & Women & Men & Shortest & Longest & Average & Youngest & Oldest & Average \\
\hline \multicolumn{10}{|l|}{ Benign form } \\
\hline 10 to 14 years & 20 & 14 & 6 & 10 & 14 & 13 & 13 & 40 & 23 \\
\hline 15 years and more & 15 & 15 & 0 & 15 & 40 & 23.6 & 18 & 30 & 23 \\
\hline Severe form & 22 & 9 & 13 & 1 & 21 & 11 & 15 & 45 & 26 \\
\hline Cerebellar form & 13 & 5 & 8 & 3 & 16 & 8.6 & 20 & 37 & 27 \\
\hline TOTAL & 70 & 43 & 27 & 1 & 40 & 14 & 13 & 45 & 24.5 \\
\hline
\end{tabular}

\section{HLA determination}

HLA typings were done in 2 laboratories. Forty-nine typings were done at the Blood Transfusion Service of the Canadian Red Cross in Montreal (F. Décary) and 21 at the Institut ArmandFrappier (G. Lamoureux). All of the control subjects were typed in the Red Cross laboratory. The standard NIH technique (Terasaki and McClelland, 1964) was used in both laboratories, for $A$ and $B$ series. Ten alleles could be determined for the HLA-A locus, while 15 alleles were determined for the HLA-B locus. For HLA-DR typing, B-cell enrichment was performed after sheep red blood cell rosetting. The sheep red blood cells had been previously treated either with neuraminidase or with aminoethylisothiouronium bromide. DR typing was done using the standardized microlymphocytotoxicity assay (Terasaki and Bernoro, 1978). HLA-DRI through DR-9 were determined. Commercially available (UCLA typing trays) and National Reference Laboratory plates (NRLT and NRLB) were used for HLA-A, B and DR typing.

\section{Statistical analysis}

The HLA-A, B and DR antigen frequencies were compared to that of the control population. For the whole group of patients, statistical significance was evaluated by the chi-square test with Yates correction with one degree of freedom. For the analysis of the sub-groups, Fisher's exact probability test was applied (Swinscow, 1978).

\section{ReSUlts}

Table 2 shows the HLA alleles distribution in the patient population studied, as well as in the controls. The only significant deviations observed were for HLA -B40 $(p<0,05)$, and DR2 ( $p$ $<0.05)$. The frequencies of HLA-A3 and HLA-B7 are within the normal range.

The distribution of selected HLA-A, B and DR alleles in clinical sub-groups of MS is indicated in Table 3. HLA-A and B antigens not shown were not significantly different from the controls. In the benign form HLA-DR2 was significantly increased only in the sub-group of 10 to 14 years of duration, whereas HLA-DR3 was significantly increased in the sub-group of 15 years or more of duration. In the severe form, both HLA-B7 and HLA-DR2 were increased to a significant level, while HLA-DR3 was normal and HLA-DR4 was decreased. In the cerebellar form, the antigen distribution was not different from 
Table 2: Distribution of HLA Alleles in MS Patients and in Controls

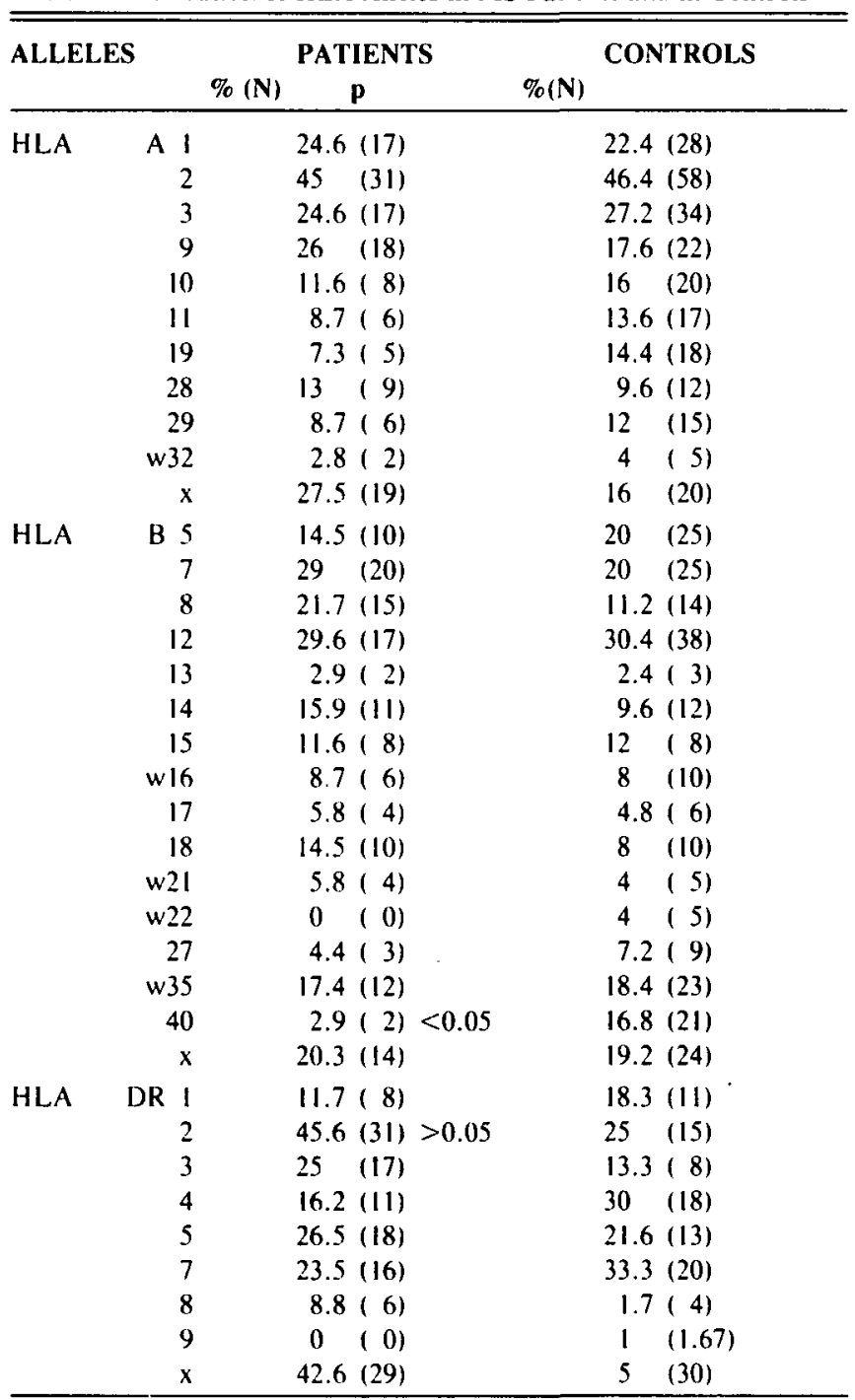

the controls. DR2 is significantly increased in the severe form when compared with the benign form of more than 15 years of duration. The difference in DR3 frequency between the latter and the former group is not significant.

Table 4 examines the distribution of HLA-DR2 and DR3 in relation to each other in the different groups. The occurrence of DR2 and DR3 together was not different than that seen in the normal control population. HLA-DR2 without DR3 was significantly increased in the severe form and in the benign group of 10 to 14 years of duration. HLA-DR3 without DR2 was associated only with the benign group of 15 years or more of duration.

Table 5 indicates the relative risk (R.R.) associated with the HLA-DR2 allele in the total population as well as in the clinical groups. The presence of DR2 confers a R.R. of 2.5 to all patients positive for that allele. Both the severe group and the benign sub-group of 10 to 14 years of duration carried a higher R.R., while a R.R. of less than 1 was associated with the benign sub-group of 15 years or more of evolution.

\section{Discussion}

MS is usually considered as a single disease entity. Indeed, the histopathologic pattern of individual plaques and the immunoglobulin modifications are invariable from one patient to another. On the other hand, numerous factors seem to indicate that MS is a-syndrome grouping several more or less closely related diseases. These factors are: age of onset (early vs. late onset), type of involvement (isolated optic neuritis, Devic's syndrome, Schilder's disease, etc.), type of evolution (remitting, progressive), rate of progress (benign, severe). There are no obvious differences in MS in females as opposed to males, nor between sporadic and familial MS.

So far, few biological factors have supported the apparent clinical heterogeneity of MS. In a Danish study, Jersild et al. (1973) found an association between DR2 and a poor prognosis. This was confirmed by Raun et al . (1980) in a Danish population. Stendhal-Brodin et al. (1979) found in a Swedish population an association between DR2, high IgG values and a malignant

\begin{tabular}{|c|c|c|c|c|c|c|c|c|}
\hline \multirow[t]{2}{*}{ HLA Alleles } & \multicolumn{2}{|c|}{ Benign (10-14 Y) } & \multicolumn{2}{|c|}{ Benign $(>14 Y)$} & \multicolumn{2}{|l|}{ Severe } & \multirow{2}{*}{$\begin{array}{l}\text { Cerebellar } \\
(\mathbf{N}: 13) \\
\%(\mathbf{N})\end{array}$} & \multirow{2}{*}{$\begin{array}{l}\text { Controls } \\
(\mathrm{N}: 125) \\
\%(\mathrm{~N}) \\
\end{array}$} \\
\hline & $\begin{array}{l}(\mathrm{N}: 20) \\
\%(\mathrm{~N})\end{array}$ & p (Fisher) & $\begin{array}{l}(\mathrm{N}: 15) \\
\%(\mathrm{~N})\end{array}$ & p (Fisher) & $\begin{array}{l}(\mathrm{N}: 22) \\
\%(\mathrm{~N})\end{array}$ & p (Fisher) & & \\
\hline A 3 & $25(5)$ & & $26.6(4)$ & & $28.5(6)$ & & $14.3(2)$ & $27.2(34)$ \\
\hline В 7 & $30(6)$ & & $13.3(2)$ & & 42 (9) & 0.040 & $21.4(3)$ & $20 \quad(25)$ \\
\hline B 18 & $15(3)$ & & $26.6(4)$ & & $9.5(2)$ & & $7.1(1)$ & $8 \quad(10)$ \\
\hline B 40 & $0(0)$ & 0.022 & $\boldsymbol{A}^{6.6(1)}$ & & $4.7(1)$ & & $\begin{array}{ll}0 & (0)\end{array}$ & $\begin{array}{cc}17 & (21) \\
& 0\end{array}$ \\
\hline DR I & $10(2)$ & & $21.4(3)$ & & $0 \quad(0)$ & & $21.4(3)$ & $18.3(11)$ \\
\hline DR 2 & $50(10)$ & 0.040 & $21.4(3)$ & & $59 \quad(13)$ & 0.009 & $35.7(5)$ & $25 \quad$ (15) \\
\hline DR 3 & $20(4)$ & & $42.8(6)$ & 0.032 & $22.7(5)$ & & $14.3(2)$ & $13.3(8)$ \\
\hline DR 4 & $40(8)$ & & $\begin{array}{ll}0 & (0)\end{array}$ & & $4.6(1)$ & 0.018 & $14.3(2)$ & $30 \quad(18)$ \\
\hline DR 5 & $20(4)$ & & $35.7(5)$ & & $22.8(5)$ & & $28.6(4)$ & 22 (13) \\
\hline DR 7 & $15(3)$ & & $28.5(4)$ & & $22.8(5)$ & & $28.6(4)$ & $33.3(20)$ \\
\hline DRw8 & $5(1)$ & & $7.1(1)$ & & $13.6(3)$ & & $7.1(1)$ & $6.7(4)$ \\
\hline
\end{tabular}

\footnotetext{
N:14

$\mathrm{N}: 60$

$\mathrm{Y}$ : years
}

Benign MS > 14 years vs. severe MS, for DR2: $p=0.006$

Benign MS $>14$ years vs. severe MS, for DR3: $p=0.250$ (not significant) 
Table 4: DR2 - DR3 Phenotypes

\begin{tabular}{llllll}
\hline \hline Phenotype & Controls & Benign 10-14 Years & Benign $>$ 14 Years & Severe & Cerebellar \\
\hline & $(\mathrm{N}: 60)$ & $(\mathrm{N}: 20)$ & $(\mathrm{N}: 14)$ & $(\mathrm{N}: 22)$ & $(\mathrm{N}: 13)$ \\
\hline DR2 + DR3 - & $12(20 \%)$ & $9(45 \%)^{*}$ & $3(21 \%)$ & $11(50 \%)^{* * *}$ & $4(28.6 \%)$ \\
DR2 + DR3 + & $1(1.6 \%)$ & $1(5 \%)$ & 0 & $2(9 \%)$ & $1(7 \%)$ \\
DR2 - DR3 + & $6(10 \%)$ & $3(15 \%)$ & $6(43 \%)^{* *}$ & $3(13.6 \%)$ & $1(7 \%)$ \\
DR2 - DR3 - & $41(68 \%)$ & $7(35 \%)$ & $5(33.3 \%)$ & $6(27.7 \%)$ & $7(57.4 \%)$ \\
\hline
\end{tabular}

$p^{*} 0.039 \quad * * 0.015 \quad * * * 0.012$

\begin{tabular}{lc}
\hline Table 5: Relative Risk for DR2 & \\
\hline \hline Group & Relative Risk \\
\hline Total group & 2.55 \\
Benign group: & \\
10-14 years & 3 \\
15 years and more & .84 \\
Severe & 4.31 \\
Cerebellar & 1.68 \\
\hline
\end{tabular}

course; the difference in DR2 frequency did not, however, reach statistical significance. Poser et al. (1981) found no difference in HLA distribution between benign and malignant MS in a German population. Engell et al. (1982) in a Danish population found that DR2 positive patients did experience a more rapid progression than DR2 negative patients. DR3 seemed to protect from this rapid progression of MS in DR2 positive patients. No association was found with other clinical parameters (severity of symptoms at onset, age of onset, remitting or progressive evolution). In contrast to these results, Delasnerie-Laupetre et al. (1982) state that in a group of 169 French patients, DR3 is an indicator of severity. Madigand et al. (1982) in a study of 261 patients from Rennes, France, have found an increase of DR2 in benign MS and an increase of DR3 in severe MS. DR2 positive patients responded to azathioprine treatment, while DR3 positive patients deteriorated under the same treatment.

In our population of MS patients HLA-DR2 is associated with the severe form of MS and HLA-DR3 is associated with the benign group of more than 14 years of duration. DR2 could be called an augmentor gene and DR3 a protector gene.

It is not surprising to find DR2 as a protector gene in some populations and as an augmentor gene in others (the same is true for DR3). Since no consistent markers have been found for the disease as a whole, the gene (or genes) influencing the prognosis of MS could be in linkage disequilibrium with different HLA-DR alleles in different populations.

The association of DR2 with both the severe form and the benign sub-group of 10 to 14 years of duration is intriguing. It could mean that DR2 positivity does not discriminate between a benign or a severe form of the disease. It could also indicate that 10 years duration is insufficient to consider a patient as having a benign form of MS. Fifteen years would be a more realistic time and DR3 is a reliable marker for such patients.

On clinical grounds, we had considered what we have called cerebellar MS as the most characteristic sub-group, because of the homogeneity of the clinical picture among the patients in this group. We considered them separately from the severe form because of the prominence of the cerebellar signs. However, no association was found for any allele in this group. This could be attributed to the small size of the group ( 13 patients). On the other hand, non-genetic factors could be responsible for the variety in the pattern of distribution of MS plaques.

The hypothesis underlying our work is that genetic factors are responsible for the variability in the clinical expression of $\mathrm{MS}$, in the distribution of plaques, or in the rate of progression of the disease. Our results suggest that this might be the case, but the associations reported to date are neither strong nor constant. The significance of the association of MS with HLA alleles is still not known. and family studies have not brought conclusive answers (Ebers, 1982).

We believe that further studies should be pursued, using larger patient populations and possibly other criteria for selecting groups. HLA typing may yield prognostic clues and help predict therapeutic responses in future clinical trials.

\section{ACKNOWLEDGEMENTS}

We are grateful to Mrs Monique Hébert for typing the manuscript. This work was supported, in part, by a grant from the Quebec division of the Canadian Multiple Sclerosis Society.

\section{REFERENCES}

Bell DA, Rigley R, Stiller CR, Clark WF, Harth M. Ebers GC (1984) HLA antigens in systemic lupus erythematosus: relationship to disease severity, age at onset and sex. J of Rheumatology 11: 475-479.

Cudworth AG, Festenstein H (1978) HLA genetic heterogeneity in diabetes mellitus. British Medical Bulletin 34: 285-289.

Delasnerie-Laupêtre N, Suet-Hubert C, Marcelli-Borg A (1982) Cerebrospinal fluid $C 2$ and HLA system in multiple sclerosis. Tissue antigens 19: 79-84.

Ebers GC (1983) Genetic factors in multiple sclerosis. Symposium on multiple sclerosis, Neurologic Clinics 1, (ed) W.B. Saunders, vol. 3: 645-654.

Ebers GC, Paty DW, Morton N (1983) Segregation and linkage analysis of HLA typing in familial multiple sclerosis. Neurology 33 (suppl. 2): 180.

Ebers GC, Paty DW, Stiller CR. Nelson RF, Seland TP, Larsen B (1982) HLA typing in multiple sclerosis sibling pairs. The Lancet 2: 88-90.

Engel AG (1979) Handbook of Clinical Neurology. (eds) Vinken P.J. Bruyn G.W. Publ.: Elsevier North Holland. Myasthenia gravis, vol. 41 (part II): 95-146.

Engell T, Raun NE, Thomsen M, Platz P (1982) HLA and heterogeneity of multiple sclerosis. Neurology 32: 1043-1046. 
Jersild C, Fog T, Hanalb GS, Svejgoard A, Thomsen M, Dupont B (1973) HL-A determinants in multiple sclerosis with special reference to clinical course. Lancet (2): 1221-1224.

Madigand M, Oger JJF, Fauchet R. Sabouraud O, Genetet B (1982) HLA profiles in multiple sclerosis suggest two forms of disease and the existence of protective haplotypes. J of Neuro Sciences 53: 519-529.

Poser S. Ritter G. Bauer HJ. Grosse-Wilde H. Kuwert EM, Raun NE (1981) HLA antigens and the prognosis of multiple sclerosis. J of Neurology 225: 219-221.

Raun NE. Fog T. Heltberg A, Platz P (1980) Correlation of the course of MS and histocompatibility antigens in Progress in multiple sclerosis research. (eds) Bauer HJ, Poser S, Ritter G Publ Springer Verlag: 456-459.
Rose AS, Ellison GW, Myers LW, Tourtelotte WW (1976) Criteria for the clinical diagnosis of multiple sclerosis. Neurology 26: 20-22.

Stendhal-Brodin L, Link H, Moller E, Norrby E (1979) Genetic basis of multiple sclerosis: HLA antigens, disease progression and oligoclonal IgG in CSF. Acta Neurol Scand 59: 297-308.

Swinscow TDV (1978) Statistics at square one. Publ British Medical Association.

Terasaki PI, Bernoco D, Park MS, Ozturk G, Iwaki Y (1978) Microdroplet testing for HLA-A, B, C and D Antigens. Amer J of Clinical Pathology 69: 103-120.

Terasaki PI, McClelland JD (1964) Microdroplet assay of human serum cytotoxins. Nature 204: 998-1000. 